\title{
COMPARING P-S CONVERSION POINT LOCATION IN ISOTROPIC AND ANISOTROPIC MEDIA
}

\author{
Fredy A.V. Artola1', Sergio A.B. Fontoura², Ricardo Leiderman ${ }^{3}$ and Jorge F.F. Sobreira ${ }^{4}$ \\ Recebido em 10 abril, 2006 / Aceito em 1 setembro, 2006 \\ Received on April 10, 2006 / Accepted on September 1, 2006
}

\begin{abstract}
The determination of the exact position of the P-S conversion point (CP) is an important issue in converted-wave seismology. Frequently, this issue is approached considering that the rock formation is isotropic. This simple approach may lead to significant errors due to the anisotropic features of the subsurface. This paper presents a comparison between the position of the $\mathrm{CP}$ obtained from the isotropic solution and the position of the $\mathrm{CP}$ considering two types of anisotropy: the transversely isotropic medium with vertical axis of symmetry, the so-called VTI, and an orthorhombic medium. In order to determine the location of the CP, the modeling program ANRAY, based on ray tracing method, was used. It is shown that for the VTI case the discrepancy between the true position of the CP and the one found by assuming isotropy can be in the order of hundreds of meters, even for offset/depth ratio, (X/Z), less than 2. On the other hand, for some particular values of Thomsen's parameters $\epsilon$ and $\delta$, it can be demonstrated that, the position of the CP practically coincides with the isotropic case. For orthorhombic symmetry (azimuthal anisotropy), the $\mathrm{CP}$, in general, is no longer located in the vertical plane defined by the source-receiver positions, i.e., the discrepancy between CP locations is expressed by an inline and an offline components. The offline component value depends on the anisotropic nature of the medium. This observation is not valid only for orthorhombic models since similar discrepancies can also be observed in cases where the anisotropy is induced by cross-dipping structures or in models with lower anisotropic symmetries.
\end{abstract}

Keywords: Converted wave, Conversion point, Anisotropy.

RESUMO. A determinação exata do ponto de conversão (PC) do modo convertido PS é um aspecto relevante da sismologia da onda convertida. Geralmente, este problema é abordado considerando-se modelos isotrópicos. Mas esta simplificação pode induzir erros significativos devido à desconsideração das características anisotrópicas do subsolo. 0 presente artigo apresenta uma comparação no que diz respeito à posição do PC nos casos isotrópico e anisotrópico. No caso anisotrópico consideram-se as seguintes simetrias: transversalmente isotrópica com eixo de simetria vertical (VTI) e ortorrômbica. Os PC's são calculados mediante a teoria do raio. Mostra-se que para a simetria VTI a discrepância entre a verdadeira posição do PC e o calculado, supondo isotropia, pode ser da ordem de centenas de metros, mesmo para uma relação afastamento-profundidade menor que 2. Por outro lado, para alguns valores dos parâmetros de Thomsen $(\epsilon \mathrm{e} \delta)$, demonstra-se que a posição do PC praticamente coincide com o caso isotrópico. Para a simetria ortorrômbica que é um caso de anisotropia azimutal, o PC, em geral, não se localiza no plano vertical definido pelas posições da fonte e do receptor, isto é, a discrepância entre a locação do PC isotrópico ou VTI com relação à ortorrômbica possui componentes paralelas e normais ao referido plano. A componente normal depende da intensidade da anisotropia do meio. Esta observação é válida não somente para modelos com simetria ortorrômbica; discrepâncias deste tipo podem ser observadas em casos onde a anisotropia é induzida por estruturas inclinadas ou, em geral, por arranjos elásticos de mais baixa simetria.

Palavras-chave: Onda Convertida, Ponto de Conversão, Anisotropia.

\footnotetext{
${ }^{1}$ Laboratório de Geofísica de Exploração de Petróleo LAGEP, CPGG. Instituto de Geociências, Universidade Federal da Bahia, Rua Barão Geremoabo S/N, Federação, 40170-290 Salvador, BA. Tels: (71) 3203-8522; 3245-8530; 8117-2013 - E-mail: fre777@zipmail.com.br

2 Grupo de Tecnologia e Engenharia do Petróleo GTEP, PUC-Rio. Rua Marquês de São Vicente 225, Edifício Padre Leonel Franca, 60 andar - Gávea, 22453-900 Rio de Janeiro, RJ. Tel: (21) 3114-1459 - E-mail: fontoura@civ.puc-rio.br

${ }^{3}$ Department of Mechanical Engineering, Boston University, Boston, MA, USA. E-mail: leider@bu.edu

${ }^{4}$ Petrobras, CENPES/DIVEX/SETEX. Cidade Universitária - Quadra 7, Ilha do Fundão, 21949-900 Rio de Janeiro, RJ. E-mail: fiori@petrobras.com.br
} 


\section{INTRODUCTION}

Converted wave seismology is being increasingly applied to imaging the subsurface as a complement to P-wave information, as a tool to classify or distinguish between rock types and fluid types and to help invert data for reservoir monitoring purposes (Davis, 2001). Recent review on the current stage of converted wave technology have been presented by Stewart et al., 2002; 2003.

Assuming that the wave conversion occurs predominantly in subsurface reflectors (Yuan et al., 1998; Zhu et al., 1999), the precise evaluation of the P-S conversion point location is essential for assembling the common conversion point gather for the purpose of velocity analysis. Exact solution exists only for simple case of homogeneous, isotropic media (Schneider Jr, 2002). The experience with isotropic layers shows that the location of the conversion point with respect to either the source or the receiver depends upon the ratio between the $\mathrm{P}$-wave and $\mathrm{S}$-wave velocities and the offset/depth ratio. For a given offset, as the depth of the reflector increases, the locus of the conversion points defines a curve that has an asymptotic value.

The proper evaluation of the conversion point location depends mainly on the possibility of dealing realistically with the most relevant physical variables related to the media. The processed results, obtained after handling the data, depend on the theoretical assumptions used in the determination of these points. For this reason, a correct calculation of these points is necessary because, rather than the CMP binning used in pure-mode processing that is generally based on geometrical criterion, commonconversion-point (CCP) binning techniques are usually applied, instead.

The strong dependence of the conversion point location on physical assumptions concerning rock velocities has been discussed in the last few years (Tessmer \& Behle, 1988; Thomsen, 1999). In general, the trend in searching for conversion point descriptions, in relatively realistic media, was initiated with crude approximations, but it is progressively moving towards a more adequate description. In the last few years, a considerable number of technical papers dealing with offset determination for converted waves in anisotropic context have been published. Although these works are limited to VTI media, they constitute an important progress in converted wave seismology. One of these important references is the work of Yuan \& Li (2001).

The relevance of anisotropic effect studies in aspects related to converted wave is not limited only to an academic research; it becomes extremely important when physical and processing parameters are estimated from real data. The recovery of these pa- rameters is impossible or very imprecise when extremely simple assumptions are made. The aim of this paper is to discuss the influence of anisotropic properties in the P-S conversion point Iocation. VTI and orthorhombic media are considered. In order to estimate the location of P-S conversion points, the 3D, anisotropic, seismic modeling computer program ANRAY, based on the ray tracing theory, was used. The solution for isotropic cases is compared to the results obtained taking anisotropy onto consideration.

Recently, Yang \& Lawton (2002) using Thomsen's approach, quantified the errors in conversion point determination when VTI media is approached with isotropic simplification, while Artola et al. (2003) analyzed the error for conversion point determination when azimuthally anisotropic media are approached with the isotropic simplification. The latter authors showed that the exact conversion point is located outside the vertical plane (offline component of displacement of the exact conversion point). This offline displacement depends mainly on the anisotropic nature of the subsurface, the offset/depth ratio X/Z and sourcereceivers geometrical arrangement. This fact, besides the inline discrepancy between the exact $\mathrm{CP}$ and that corresponding to isotropic simplification, can affect significantly the spatial resolution of subsurface seismic images.

\section{P-S CONVERSION POINT IN ANISOTROPIC MEDIA}

The behavior of the P-S mode in anisotropic media is not a simple subject. Vavryčuk (1999) and Jíleck (2001) have shown some of the inherent complexities of the propagation of this special type of wave. If we consider some of these aspects, it is possible to predict some relevant and "non-expected" properties of the P-S wave propagation in layered media, though, in a strict sense, the term "non-expected" only has meaning for people unfamiliar to seismic anisotropy or other seismic features of complex media.

In non-isotropic and non-VTI media context, one of the "nonexpected" properties is the special characteristic of the CP location. The latter is because, in general, the CP is located outside the vertical plane defined for the source-receivers line, even in homogeneous media (Figure 1). In spite of this, it is important to indicate that this is not something that happens only when the C-W is studied, because the occurrence of reflection points outside the vertical plane can be expected also in the context of the PP mode propagation in isotropic inhomogeneous media. Examples can be found in Gajewski \& Pšenčík (1990). The offline displacement of the location of the reflection points happens because, in some cases, Snell's law cannot be satisfied in the vertical plane. For 


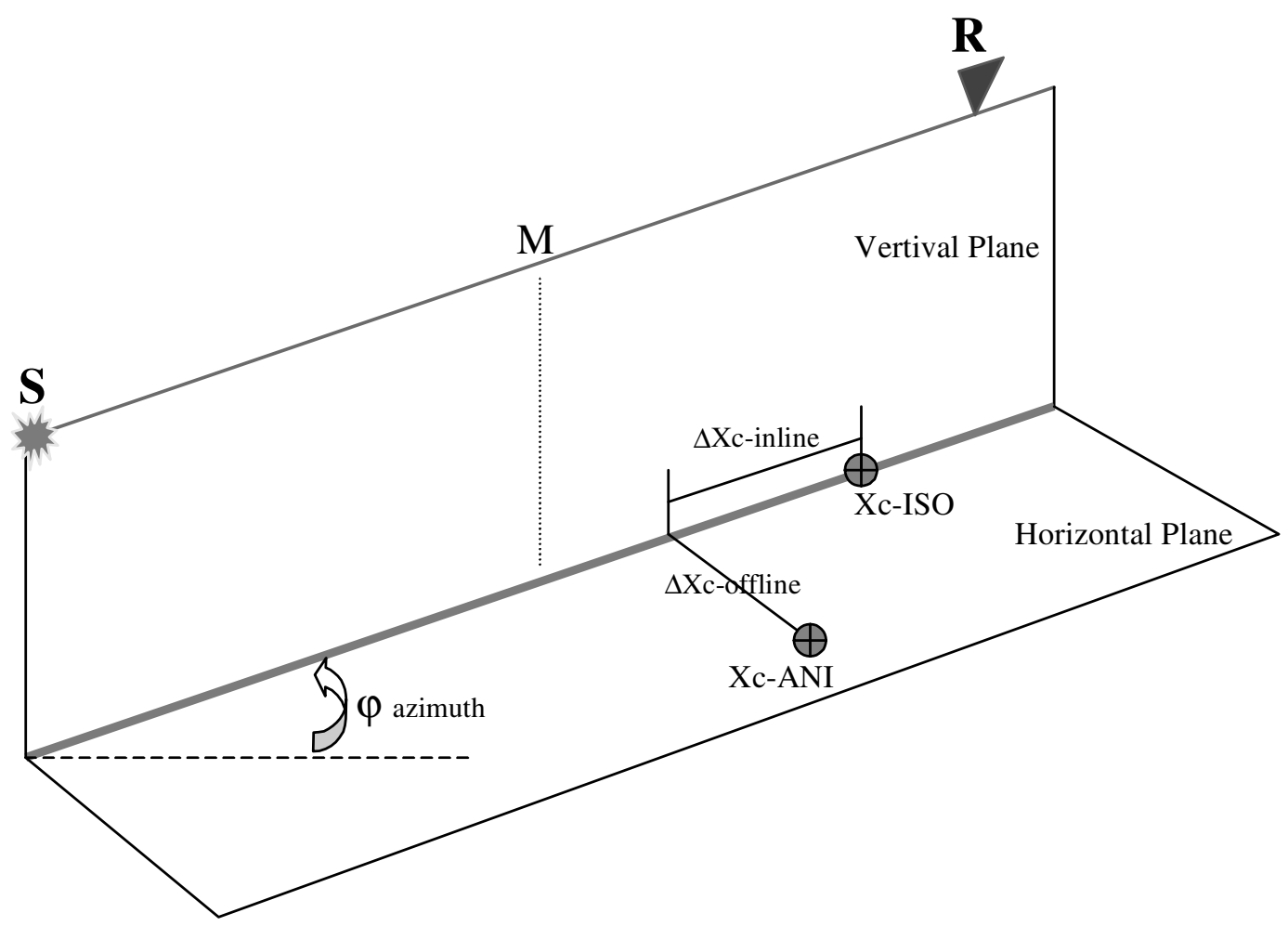

Figure 1 - Conversion point in isotropic and azimuthally anisotropic media.

C-W case, there is a significant distance between the exact location of the CP and the vertical plane and, the measurement of this distance depends on the anisotropic nature of the subsurface, the offset/depth ratio $X / Z$ and the azimuth of the source-receivers line.

In this work, we show examples of the CP distribution in VTI and orthorhombic (azimuthal anisotropy) media and we compare those cases with the CP location in isotropic media. For this purpose, we built a VTI model using Thomsen's (1986) parameters from an initial isotropic model. The orthorhombic model is built from the VTI model by introducing a system of synthetic vertical cracks in the medium. The compliance tensor associated with this orthorhombic model can be calculated with the aid of the linear slip crack model, as described by Schoenberg \& Helbig (1997) and Schoenberg \& Douma (1988), or with penny-shaped crack model according to Hudson (1981).

\section{VTI model}

The starting model consists of a single $1 \mathrm{~km}$-thick isotropic homogeneous layer with $V p=3 \mathrm{~km} / \mathrm{s}, V s=1.5 \mathrm{~km} / \mathrm{s}$ and $\rho=2 \mathrm{~g} / \mathrm{cm}^{3}$. By using $V p$ as $V p_{0}$, and $V s$ as $V s_{0}$, instead, that is the vertical velocities in a VTI model, one can determine a set of stiffness tensors for several combinations of $\epsilon, \delta$ and $\gamma$ (Thomsen's parameters). The conversion points were determined using the ray tracing method available in the program ANRAY ${ }^{\circledR}$, version 4-2.

The source and receivers array are composed of 40 inline receivers equally spaced 50 meters apart, resulting in a minimum offset of $50 \mathrm{~m}$ and in a maximum offset of $2 \mathrm{~km}$. For this special symmetry, the conversion point is located in the vertical plane (Figure 2) and the particle displacement of the converted wave PSV is polarized in the incident plane. As a result of the latter, the discrepancy between $X c_{V T I}$ and $X c_{I S O}$ is a distance measured in the vertical (inline) plane. Hence, this discrepancy can be calculated subtracting the inline coordinate of $X c_{I S O}$ from the inline coordinate of $X c_{V T I}\left(\Delta X c=X c_{V T I}-X c_{I S O}\right)$.

The discrepancy between $X c_{V T I}$ and $X c_{I S O}$ for several values of $\epsilon$ and $\delta$ is plotted in Figure 3 (a)-(d). In these figures, it can be seen that the discrepancy depends on values associated with the Thomsen parameters as well as on the offset-depth ratio. The value and direction of the conversion point displacement depends on the relationship between $\epsilon$ and $\delta$. For a fixed value of $\epsilon$, a change in the value of $\delta$ can result in $X c_{V T I}$ being closer to 


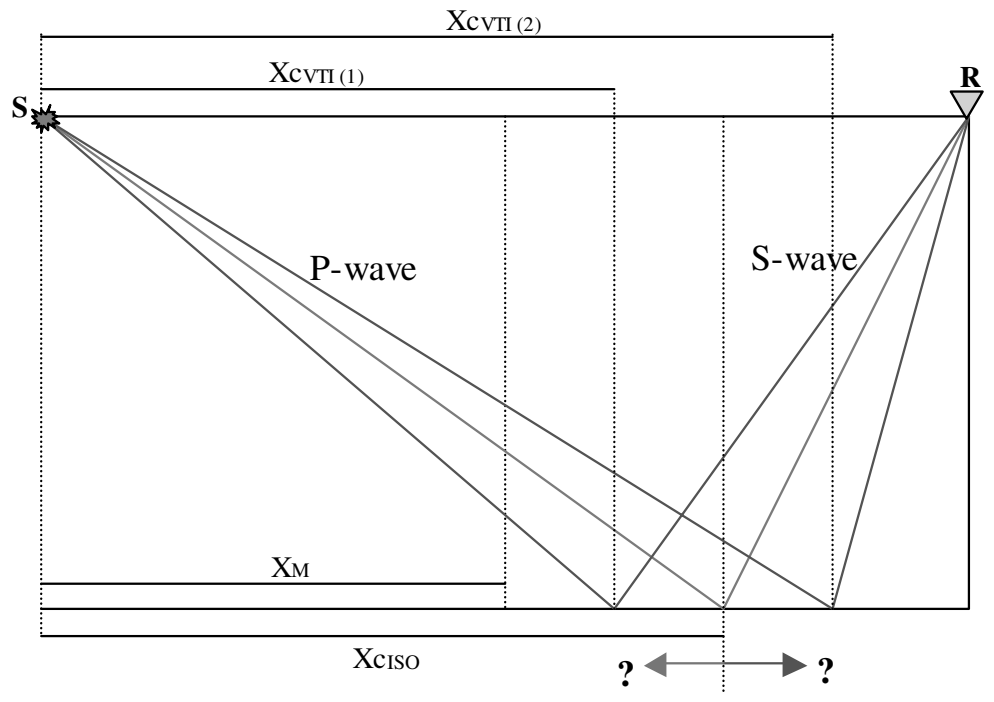

Figure 2 - Conversion point in isotropic and VTI media.

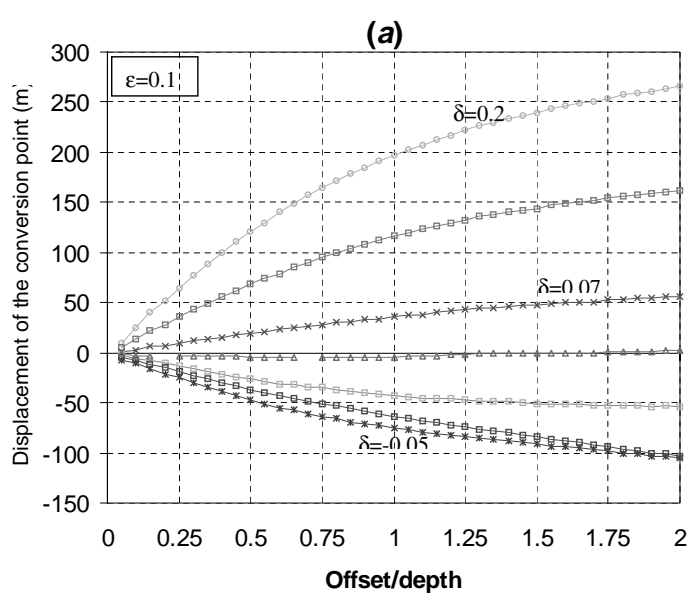

(c)

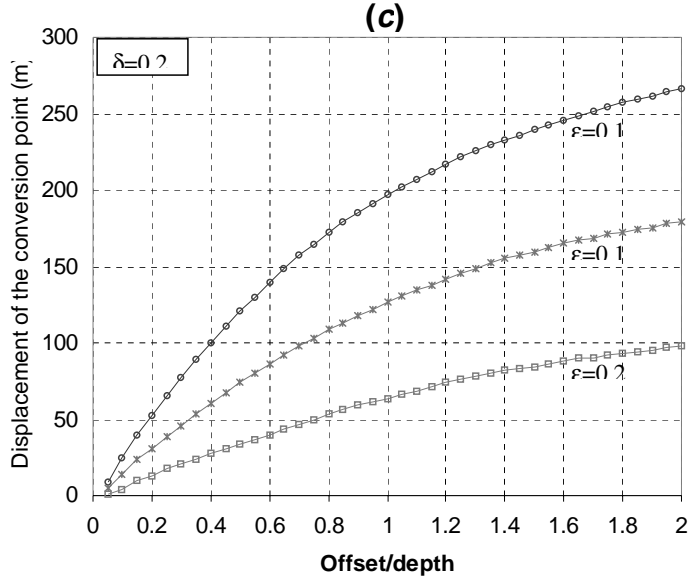

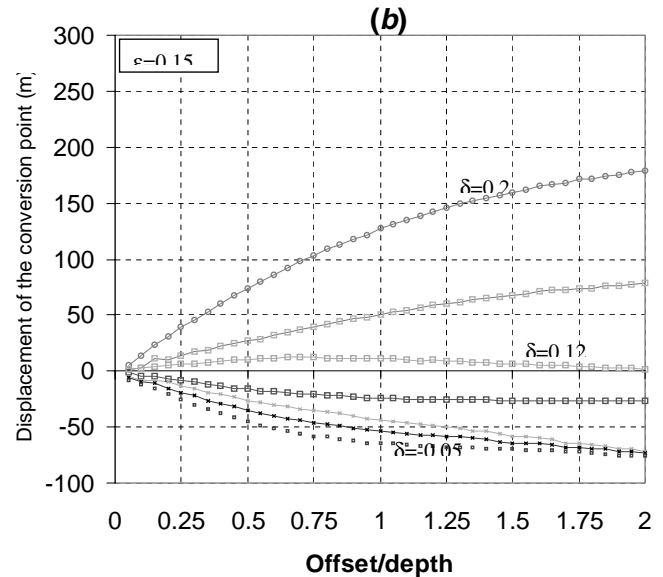

(d)

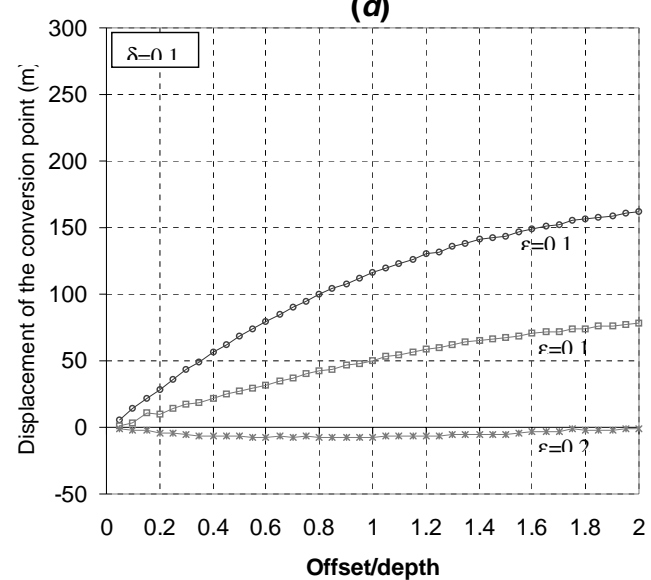

Figure 3 - VTI model. Displacement of the conversion point in comparison to the isotropic case. Model with $\epsilon$ fixed in 0.1 (a) and in 0.15 (b), and with $\delta$ fixed in 0.2 (c) and in 0.15 (d). 


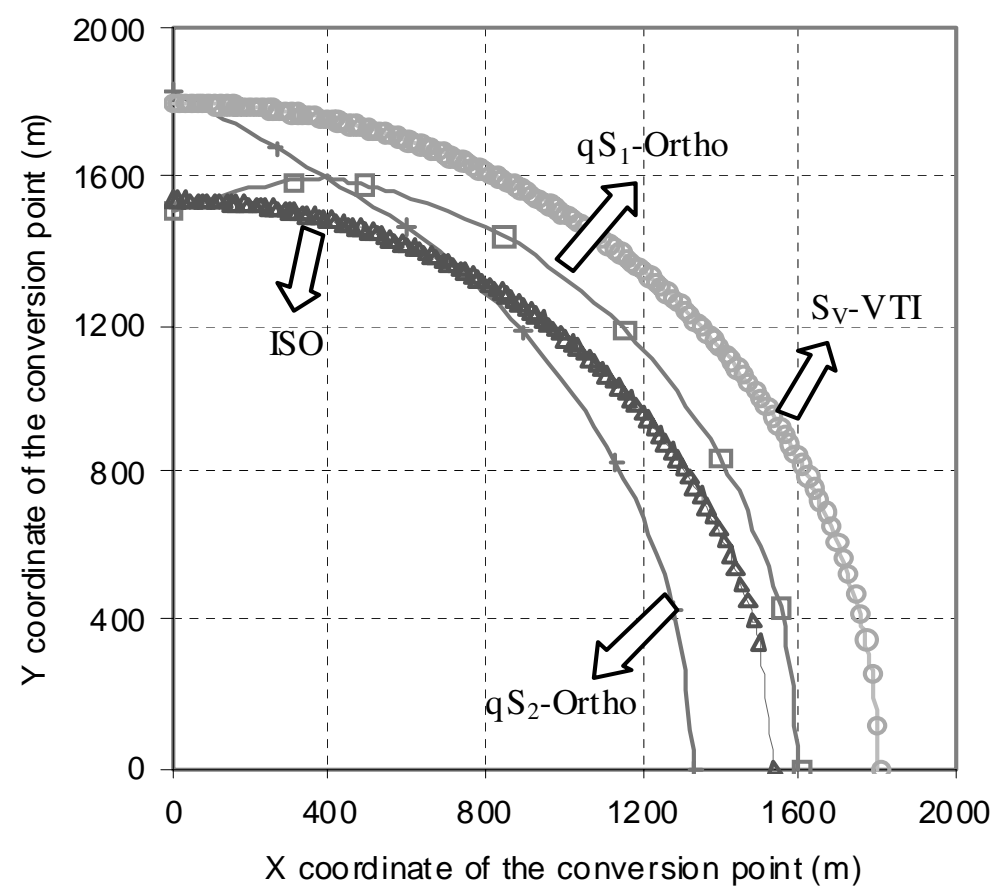

Figure 4 - Multiazimuthal conversion point for orthorhombic, VTI and isotropic cases.

either the source or the receiver, when compared to $X c_{I S O}$. On the other hand, certain combinations of $\epsilon$ and $\delta$ result in $X c_{V T I}$ being next to $X c_{I S O}$. It can be seen in Figures $3(\mathrm{a})$ and $(\mathrm{b})$, that for the pairs $(\epsilon, \delta) \rightarrow(0.1,0.075) ;(0.15,0.12), X c_{V T I}$ is very close to $X c_{I S O}$. This shows that, in some special cases, the $\mathrm{VTI}$ and isotropic CP's can be practically the same. It is possible that in some cases, the good results obtained in converted-wave processing, assuming isotropy, might be associated to this fact.

\section{Orthorhombic Model}

In order to evaluate the effect of anisotropy in the location of CP in more realistic cases, a new model was built by introducing, in the VTI model, a vertical crack system with crack density $(\eta)=0.1$ (weak anisotropy). Due to the presence of the cracks, the medium can be considered as being orthorhombic, i.e., it is no longer azimuthally invariant. In this case, in general, the polarization vectors of the converted $q S_{1}$ and $q S_{2}$ waves are rotated by an angle $\theta$, when compared to the corresponding converted $S V$ and $S H$ waves. In addition to this, as we mentioned already, because of Snell's Law, the conversion point is located outside the vertical plane. This way, the waves reaching the receivers were reflected from a point in the reflector away from this vertical plane. Consequently, $X c_{O R T H O}$ is shifted from $X c_{V T I}$ and $X c_{I S O}$ by inline and offline components. The offline component depends on the perturbation characteristics introduced to azimuthally invariant models. Figure 4 shows the azimuthal variation of the conversion point coordinates associated to $q S_{1}$ and $q S_{2}$ for a fixed offset of $2 \mathrm{~km}$ and the ratio offset $/$ depth $=2$. The conversion point coordinates of the P-SV-mode in correspondent VTI and isotropic cases are also plotted.

The inline and offline components of the displacement between $X c_{O R T H O}$ and $X_{I S O}$ are plotted in Figure 5. From these results, it can be seen that the components displacement (inline and offline) of the two converted modes are different when measured with respect to the isotropic CP. If the processing were carried out by means of algorithms based on isotropic assumptions, the error in the location of the CP for certain values of azimuth would be, for this example, in the order of hundreds of meters (up to $15 \%$ of the distance source-receiver). The impact of this error in the P-S acquisition design and in the spatial resolution of the images related to these modes can be considerable, affecting both converted modes to different extents.

\section{CONCLUSIONS}

Given the anisotropic effect on the CP location, in general, for non-isotropic and non-VTI models, the CP is not placed in the vertical plane defined by the inline arrangement of source-receivers. On the other hand, the CP determined for VTI models, when com- 
(a)

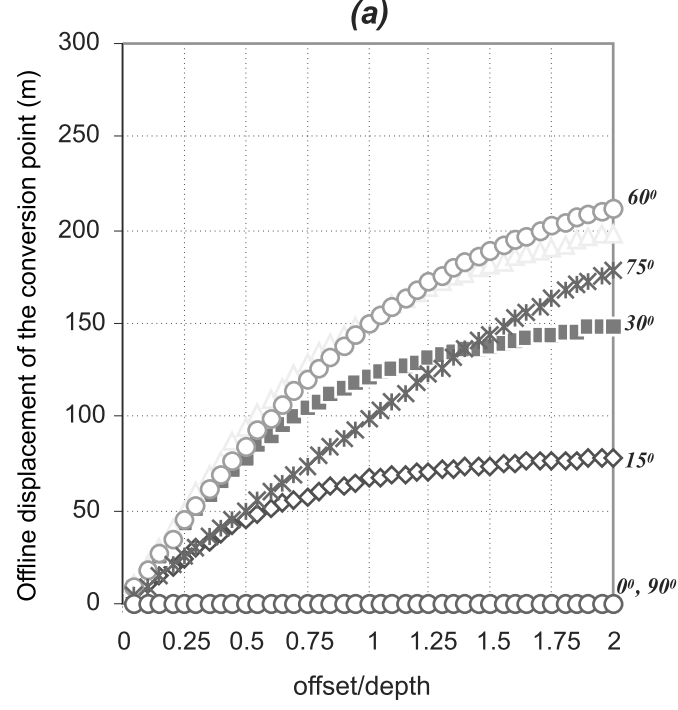

(c)

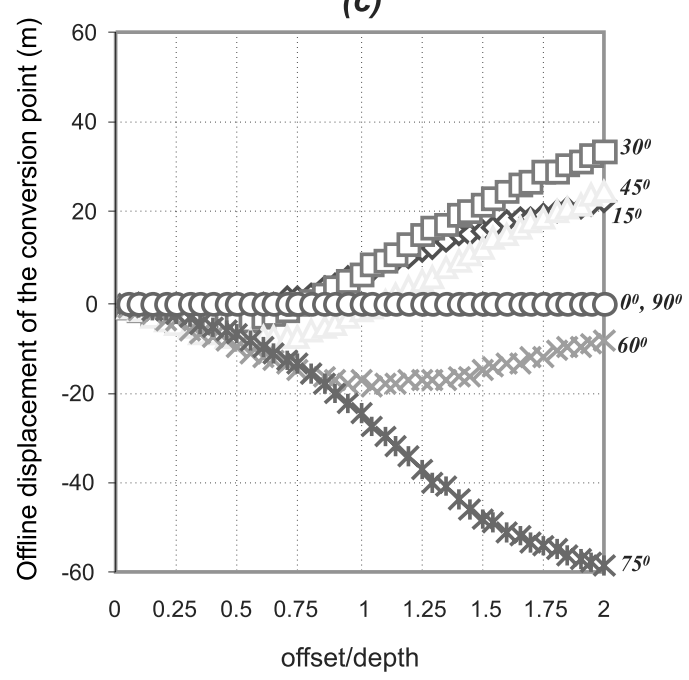

(b)

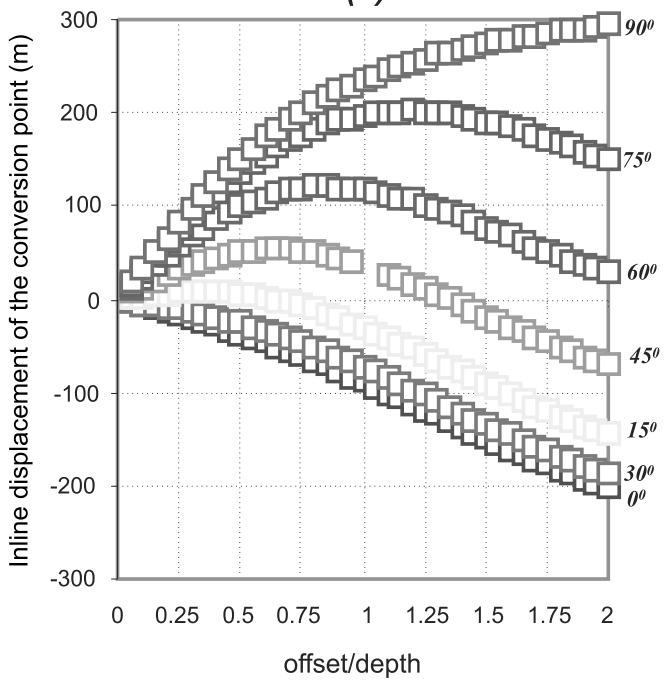

(d)

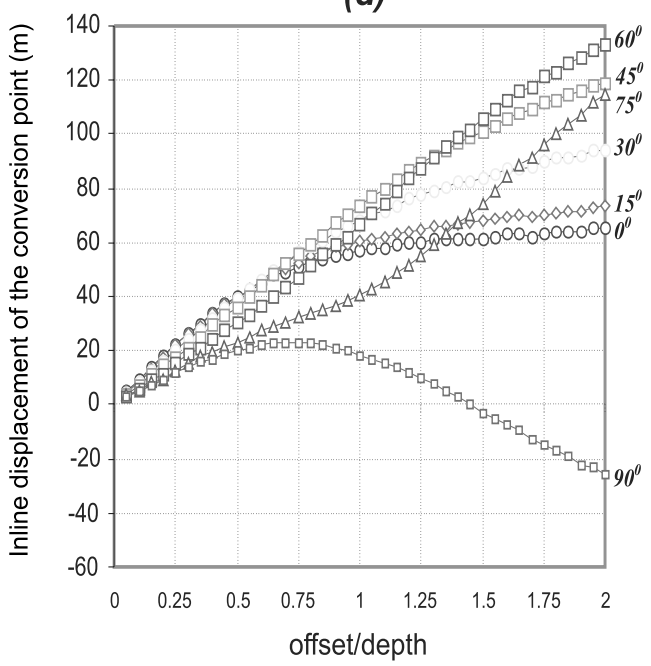

Figure 5 - Offline and inline displacements of the anisotropic conversion point from isotropic case. The curves correspond to several values of azimuth with respect to the direction normal to the cracks. The qS2 component is shown in (a) and (b), and qS2 in (c) and (d).

pared to the isotropic case, has a displacement in the vertical plane. When one considers orthorhombic models, CP's have a displacement composed by inline and offline components compared to the isotropic and VTI cases. It is important to highlight that there are combinations of Thomsen's parameters $\epsilon, \delta$, in VTI cases, for which $X c_{V T I}$ is very close to $X c_{I S O}$.

For more realistic cases, orthorhombic models for instance, the offline component of displacement in CP location depends mainly on the anisotropic nature of the subsurface, the offset/depth ratio X/Z and the source-receivers geometrical arrangement. The values of offline displacement components of $\mathrm{CP}$ can be much greater than the ones shown here, if more complex models are considered, in which the crack systems are oblique to the vertical axis. This fact can have important implications on P-S acquisition design. On the other hand, if simple isotropic assumptions were followed, the spatial resolution of subsurface seismic images can be considerably affected.

\section{ACKNOWLEDGEMENTS}

The authors would like to thank the Seismic Acquisition Group of the Oil Recovery Advanced Program of PETROBRAS (PRAVAP 19) for the financial support. Special thanks go to Ivan Pšenčík 
for helping with the software ANRAY $\odot$ and to Vladimir Alvarado for the critical review of the manuscript.

\section{REFERENCES}

ARTOLA FAV, FONTOURA SAB, LEIDERMAN R \& SILVA MBC. 2003. P-S conversion point in anisotropic media: errors due to isotropic considerations. $65^{\text {th }}$ EAGE Conference, Expanded Abstracts.

DAVIS TL. 2001. Multicomponent seismology - The next wave. Geophysics, 66(1): 49.

GAJEWSKI D \& PŠENČÍK I. 1990. Vertical seismic profile synthetics by dynamic ray tracing in layered anisotropic structures. Journal of Geophysical Research, 95: 11301-11315.

HUDSON JA. 1981. Wave speeds and attenuation of elastic waves in material containing cracks. Geophys. J. R. Astr. Soc., 64: 133-150.

JILEECK P. 2001. Modeling and inversion of converted-wave reflection coefficients in anisotropic media: A tool for quantitative AVO analysis, Ph.D. Thesis, CWP, Colorado School of Mines. 154 pp.

SCHOENBERG M \& DOUMA J. 1988. Elastic wave propagation in media with parallel fractures and aligned cracks. Geophysical Prospecting, 36 : 571-589.

SCHOENBERG M \& HELBIG K. 1997. Orthorhombic media: Modeling elastic wave behavior in vertical fractured earth. Geophysics, 62: 19541974.

SCHNEIDER Jr WA. 2002. A simple, exact solution for the P-SV wave conversion point via prestack migration, Geophysics, 67: 1634-1636.
STEWART RR, GAISER JE, BROWN JR \& LAWTON DC. 2002. Convertedwave seismic exploration: Methods, Geophysics, 67: 1348-1363.

STEWART RR, GAISER JE, BROWN JR \& LAWTON DC. 2003. Convertedwave seismic exploration: Applications, Geophysics, 68: 40-57.

TESSMER G \& BEHLE A. 1988. Common reflection point data-stacking for converted-waves: Geophysical Prospecting, 36: 671-688.

THOMSEN L. 1986. Weak elastic anisotropy: Geophysics, 51: 19541966.

THOMSEN L. 1999. Converted-wave reflection seismology over inhomogeneous anisotropic media: Geophysics, 64: 678-690.

VAVRYČUK V. 1999. Weak-contrast reflection/transmission coefficients in weakly anisotropic elastic media: P-wave incidence. Geophys. J. Int. 138: 553-562.

YANG J \& LAWTON D. 2002. Mapping the P-S conversion point in vertical transversely isotropic (VTI) media, $72^{\text {nd }}$ Annual International Meeting, SEG Expanded Abstracts, 1006-1009.

YUAN J, LI XY, ZIOLKOWSKI A \& STRIJBOS F. 1998. Processing 4C seafloor seismic data: A case example from North Sea: $68^{\text {th }}$ Annual Internat. Mtg., Soc. Expl. Geophys., Expanded Abstracts, I: 714-717.

YUAN J \& LI XY. 2001. PS-wave conversion point equations for layered anisotropic media: $71^{\text {st }}$ Annual Internat. Mtg., Soc. Expl. Geophys., Expanded Abstracts, 157-160.

ZHU X, ALTAN S \& LI J. 1999. Recent advances in multicomponent processing. The Leading Edge, 18: 1283-1288.

\section{NOTES ABOUT THE AUTHORS}

Fredy Alex Villaorduña Artola. BSc Geological Engineering, 1992 (UNI-Peru); MSc Applied Geophysics, 1997 (UNB); PhD Applied Geophysics, 2000 (UNB). Visited CPGG/UBBA as a postdoc researcher in 2001. Areas of interest are seismic modeling, seismic anisotropy, ray theory, multicomponent seismology, rock physics and time-lapse seismic reservoir monitoring. Worked in various aspects of these subjects since 1995.

Sérgio Augusto Barreto da Fontoura. PhD Geomechanics,1980, University of Alberta. Areas of interest are rock mechanics and borehole stability.

Ricardo Leiderman. PhD Mechanical Engineering, 2002, PUC-Rio. Area of interest is wave propagation in poroelastic media.

Jorge Fiori Fernandes Sobreira. MSc Geophysics. Area of interest is multicomponent seismology. 